\title{
Rationale and design of the Clinical Evaluation of MAgnetic Resonance imaging in Coronary heart disease 2 trial (CE-MARC 2): A prospective, multi-centre, randomized controlled trial of diagnostic strategies for suspected coronary heart disease
}

\author{
David P Ripley ${ }^{1}$, Julia Brown², Colin C Everett ${ }^{2}$, Petra Bijsterveld ${ }^{1}$, Simon Walker ${ }^{3}$, Mark Sculpher ${ }^{3}$, Gerry P McCann $^{4}$, \\ Colin Berry ${ }^{5}$, Sven Plein ${ }^{1}$, John P Greenwood ${ }^{1 *}$
}

From 19th Annual SCMR Scientific Sessions

Los Angeles, CA, USA. 27-30 January 2016

\begin{abstract}
Background
A number of investigative strategies exist for the diagnosis of coronary heart disease (CHD). Despite the widespread availability of non-invasive imaging, invasive angiography is commonly used early in the diagnostic pathway. Consequently, approximately $60 \%$ of angiograms reveal no evidence of obstructive coronary disease. Reducing unnecessary angiography has potential financial savings and avoids exposing the patient to unnecessary risk. There are no large scale comparative effectiveness trials of the different diagnostic strategies recommended in international guidelines and none that have evaluated the safety and efficacy of cardiovascular magnetic resonance (CMR).
\end{abstract}

\section{Methods}

CE-MARC 2 is a prospective, multi-centre, 3 -arm parallel group, randomized controlled trial of patients with suspected CHD (pre-test likelihood 10-90\%) requiring further investigation. 1200 patients will be randomized on a 2:2:1 basis to receive 3.0 Tesla CMR-guided care, single photon emission computed tomography (SPECT) guided care (according to ACC/AHA appropriate-use criteria) or National Institute for Health and Care Excellence

'Multidisciplinary Cardiovascular Research Centre (MCRC) \& Leeds Institute of Cardiovascular and Metabolic Medicine, University Of Leeds, Leeds, UK Full list of author information is available at the end of the article guidelines-based management. The primary (efficacy) endpoint is the occurrence of unnecessary angiography as defined by a normal $(>0.8)$ invasive fractional flow reserve. Safety of each strategy will be assessed by 3-year major adverse cardiovascular event rates. Cost effectiveness and health related quality of life (HRQoL) measures will be performed.

\section{Results}

The CE-MARC 2 trial will provide comparative efficacy and safety evidence for three different strategies of investigating patient with suspected CHD, with the intension of reducing unnecessary invasive angiography rates.

\section{Conclusions}

Evaluation of these management strategies has the potential to improve patient care, HRQoL and the cost effectiveness of CHD investigation.

\footnotetext{
Authors' details

${ }^{1}$ Multidisciplinary Cardiovascular Research Centre (MCRC) \& Leeds Institute of Cardiovascular and Metabolic Medicine, University Of Leeds, Leeds, UK. ${ }^{2}$ Clinical Trials Research Unit, University of Leeds, Leeds, UK. ${ }^{3}$ Centre for Health Economics, University of York, York, UK. ${ }^{4}$ Department of Cardiovascular Sciences, University of Leicester, Leicester, UK. ${ }^{5}$ BHF Glasgow Cardiovascular Research Centre, University of Glasgow, Glasgow, UK.
} 


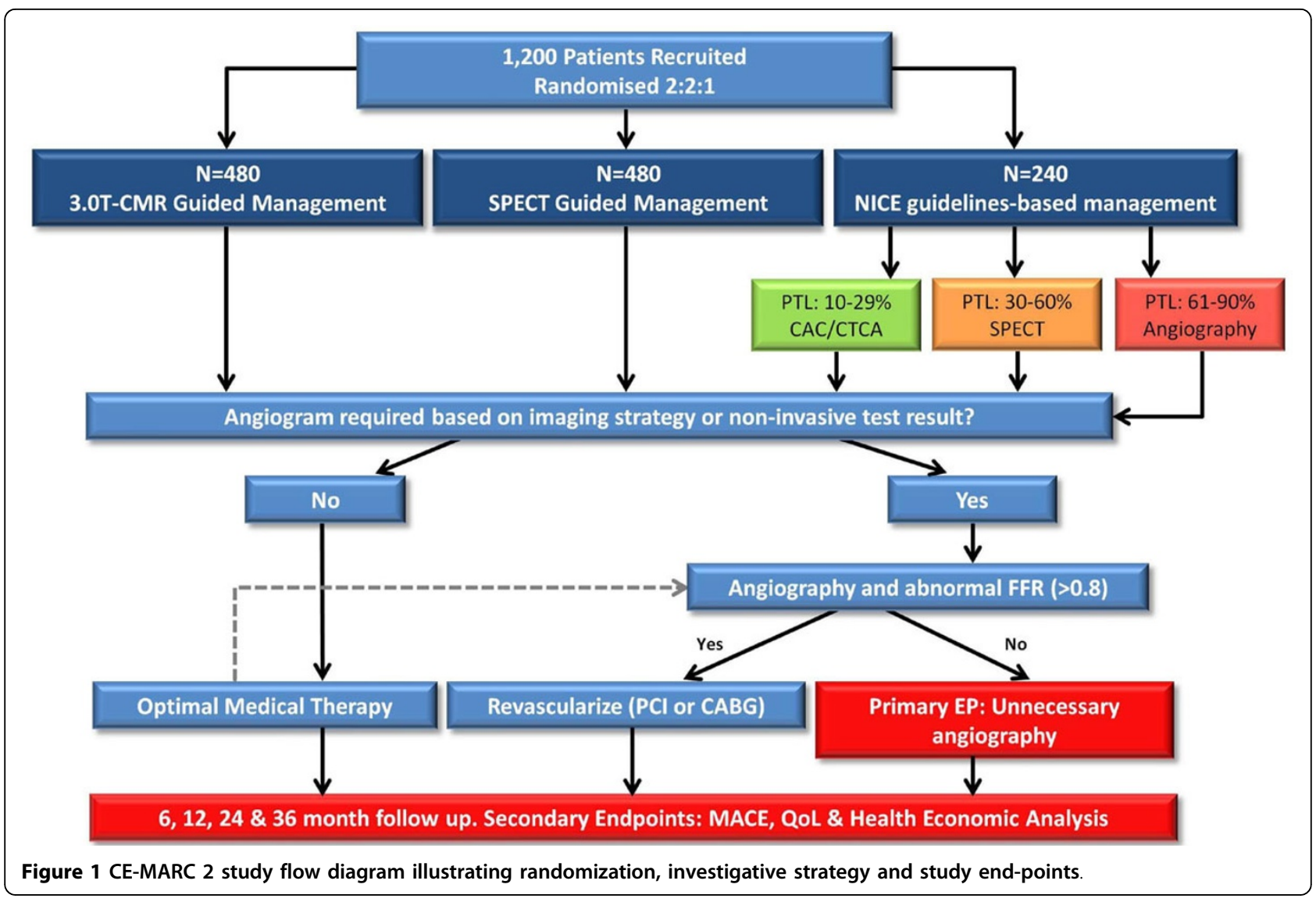

Published: 27 January 2016

doi:10.1186/1532-429X-18-S1-P75

Cite this article as: Ripley et al:: Rationale and design of the Clinical Evaluation of MAgnetic Resonance imaging in Coronary heart disease 2 trial (CE-MARC 2): A prospective, multi-centre, randomized

controlled trial of diagnostic strategies for suspected coronary heart disease. Journal of Cardiovascular Magnetic Resonance 2016 18(Suppl 1): P75.

Submit your next manuscript to BioMed Central and take full advantage of:

- Convenient online submission

- Thorough peer review

- No space constraints or color figure charges

- Immediate publication on acceptance

- Inclusion in PubMed, CAS, Scopus and Google Scholar

- Research which is freely available for redistribution 